\title{
AN EXPERIMENT IN THE IMPORTATION OF BENEFICIAL INSECTS.
}

BY F. M. WEBSTER, WOOSTER, OHIO.

In the February number of the Canadian Entomologist I gave the results of an experiment in the exportation of a few of our native lady beetles to South Africa. I now have the pleasure of giving the result of an experiment in the importation of some South African lady beetles.

March 27 th, Mr. C. W. Mally, Assistant Government Entomologist, sent me several specimens of Exochomus nigromaculatus, and quite a large number of two smaller, unnamed species. All of these attack more especially the Mealy bug, Dactylopius, in their native home. The consignment was made by simply fastening twigs of Oleander very badly affected with Mealy bug, to the bottom of the box, and putting the lady beetles among them. The package reached me April 23rd, and, strangely enough, there were but very few of the specimens that were not alive and active. The importation was thus an entire success. Mr. Mally writes me that, about Cape Town, these lady beetles are kept considerably reduced in numbers by a small Hymenopterous parasite. In releasing the lady beetles, we took precautions not to allow these parasites to escape, so that the insect, if it secures a foothold in this country and stands the climate, will have no natural enemies to hold it in check. In cases like this, and more especially in the one previously recorded, any permanent establishment of these insects would be to a certain extent accidental; that is, in the former case the lady beetles were not sent out to prey upon an insect in South Africa, whose original home was in America. In the present instance these lady beetles will probably destroy the Mealy bugs in conservatories, but it is yet to be determined whether they can withstand the rigours of our northern climate in the open. Very many injurious species are introduced and become established in this country through pure accident, and it would seem that we might expect an occasional instance of this kind to occur among beneficial insects intentionally introduced; but the principal motive in these two transactions has been, not so much with a view of colonizing these insects in the respective countries, as to secure information that would be of service to us in future transactions of this kind.

These experiments cost practically nothing, and through them we shall be able to get a better idea of the best methods of sending beneficial insects from one country to another, so that when an opportunity does 
occur, where we may feel reasonably sure of success, we shall be in better shape to send insects of this character in a manner most likely to enable them to reach their destination with the least number of fatalities while in transit. It is by this continually doing something that we are some day * enabled to accomplish much.

\section{THE LINNAAN GENUS GRYLLUS-ADDITIONS AND COR- RECTIONS.}

Quite recently I was kindly informed by Mr. S. H. Scudder, that in my paper on the divisions and species of the original genus Gryllus (Canad. Ent, XXXIII., pp. I I8-I2I), I had overlooked the fact that Fieber's paper had appeared in Lotos in 1853 . With the information furnished by Mr. Scudder, I examined the work, and found that Mecostethus appeared in the May number, on page 99, and Pachytylus and $P s o p \bar{h} u s$ in the June number, on pages I $2 \mathrm{I}$ and $\mathrm{r} 22$, respectively. This fact further clinches the Linnaan Locusta on Fischer's Stenobothrus.

The date given for Thunberg's Gomphocerus is erroneous, and should be 18 I 5 , while the original spelling of Bolivar's "Humbella" is Humbe. James A. G. Rehn, Philadelphia.

Erratum.-Page s 29, line I $_{5}$, for “Ziphidium" read Xiphidium. 